\title{
Mental and social health in the German old age population largely unaltered during COVID-19 lockdown: results of a representative survey
}

Running head: Old age mental and social health in COVID-19 lockdown

Susanne Röhr1, PhD, Ulrich Reininghaus²,3,4, PhD, Prof., Steffi G. Riedel-Heller ${ }^{1}$, MD, Prof.

${ }^{1}$ Institute of Social Medicine, Occupational Health and Public Health (ISAP), Medical Faculty, University of Leipzig, Leipzig, Germany

2Department of Public Mental Health, Central Institute of Mental Health, Medical Faculty Mannheim, Heidelberg University, Mannheim, Germany

${ }^{3}$ Centre for Epidemiology and Public Health, Health Service and Population Research Department, Institute of Psychiatry, Psychology \& Neuroscience, King's College London, London, UK

${ }^{4}$ ESRC Centre for Society and Mental Health, King's College London, London, UK

\section{Correspondence:}

Dr. rer. med. Susanne Röhr, M.Sc.

Institute of Social Medicine, Occupational Health and Public Health (ISAP),

Medical Faculty, University of Leipzig

Philipp-Rosenthal-Straße 55,

04103 Leipzig, Germany

Phone: +49 34197 24568, Fax: +49 3419724569

Email: Susanne.Roehr@medizin.uni-leipzig.de 


\section{Abstract}

Background: Older individuals are at increased risk of a severe and lethal course of COVID19. They have typically been advised to practice particularly restrictive social distancing ('cocooning'), which has sparked much debate on mental and social health consequences in older individuals. We aim to provide evidence.

Methods: A computer-assisted standardized telephone interview was conducted in a randomly selected and representative sample of the German old age population ( $n=1,005$; age $\geq 65$ years) during lockdown in April 2020. Assessments included sociodemographic factors, aspects of the personal life situation during lockdown, attitudes towards COVID-19, and standardized screening measures on depression, anxiety, somatization, posttraumatic stress, perceived stress, loneliness and social support. Sampling-weighted descriptive statistics and multiple multivariable regression analyses were conducted.

Results: Participants were $M=75.5$ ( $S D=7.1$ ) years old; $56.3 \%$ were women. At data collection, COVID-19 lockdown had been in force for $M=28.0$ ( $S D=4.8$ ) days. Overall, older individuals were worried about COVID-19, but supportive of the lockdown. Mean scores and prevalence estimates of measured mental and social health variables were comparable to figures reported before the pandemic, except slightly higher perceived stress and higher perceived social support. There were only few significant associations of aspects of the personal life situation during lockdown and attitudes towards COVID-19 with mental and social health variables, while resilience explained a large amount of variance.

Conclusions: In the short-term, the mental and social health of the German old age population was largely unaltered during COVID-19 lockdown, suggesting resilience against the challenging pandemic situation. Our results refute common ageist stereotypes of "the weak and vulnerable elderly" that were present during the pandemic. Long-term observations are needed to provide robust evidence.

Keywords: COVID-19 lockdown, COVID-19 pandemic, mental health, social health, old age, epidemiology, survey 


\section{Background}

In 2020, the majority of the world's population is experiencing unprecedented restrictions to their lifestyles due to mass quarantine measures imposed to slow the spread of the newly emerged coronavirus Severe Acute Respiratory Syndrome Coronavirus 2 (SARS-CoV-2), causing the respiratory disease Corona Virus Disease 2019 (COVID-19) [1]. Germany was among the early affected countries with the first COVID-19 case being reported on January, $28^{\text {th }} 2020$, followed by a rapid increase of infections. Nationwide comprehensive contact restrictions and lockdowns became effective on March 215t/22nd 2020 . By end of May 2020, 181,482 COVID-19 cases and 8,500 deaths (4.7\%) were recorded [2].

Early on, the World Health Organization (WHO) published a statement on psychosocial considerations during the COVID-19 outbreak, raising awareness about the potential psychological impact of mass quarantine measures [3]. Evidence from previous serious virus outbreaks, e.g. the SARS pandemic 2003/2004, showed negative psychosocial health consequences of mass quarantine measures, including anxiety, depressive symptoms, social isolation, loneliness, and a lack of social support [4]. A recent study assessing the mental health impact of COVID-19 lockdowns in adults across 12 heavily affected countries (incl. USA, Spain, Italy, France, Germany, UK, Iran, Turkey, and Switzerland) found, that average scores on psychological disturbance, posttraumatic stress disorder (PTSD), and depression exceeded mild-risk thresholds [5]. Notably, the authors reported that higher age was associated with lower psychological distress, suggesting that older individuals better adapt to challenging life events.

Focusing in particular on the mental and social health of the elderly during the COVID-19 pandemic is important for several reasons. As noted earlier, older individuals and individuals with pre-existing health conditions (most of them highly prevalent in older age, including diabetes and hypertension), constitute a vulnerable high-risk group for a severe and lethal course of COVID-19. By the end of May 2020, individuals above 70 years of age accounted for $86 \%$ of all deaths due to COVID-19 in Germany [2]. Therefore, the government advised older individuals to practice particularly restrictive social distancing ("cocooning"), e.g. avoiding going outside, avoiding having direct contact with grandchildren or buying groceries 
themselves. This, as well as potential worry or anxiety about contracting COVID-19, may lead to social withdrawal and isolation, which are associated with adverse health outcomes and increased mortality [6]. Reduced social participation may also result in cognitive and functional decline [7]. Then again, older individuals may have higher resilience and therefore may cope better with adverse life events because of having mastered crises throughout life [8]. Moreover, despite older individuals being at higher risk of a severe course of COVID-19, it is important not to victimize a population group merely based on age. On a societal level, COVID-19 has sparked much controversial debate on how older individuals are presented, because some of the public discourse during the pandemic disparages older people as being more expendable than people of other age groups [9]. Open ageism, i.e. discrimination against older people due to negative and inaccurate stereotypes, has been evident e.g. through the trending social media hashtag "\#BoomerRemover", which suggested the death of older individuals would not be as important as the loss of younger life [9]. Such ageist stereotypes can accentuate the exclusion of, and prejudice against, older adults, which in turn may complicate dealing with the COVID-19 crisis for older people [10]. The well-being of older individuals during COVID-19 lockdown has sparked much debate; however, there is a paucity of reliable data providing evidence for the many controversial claims.

\section{Study aims}

Against this background, we aimed to investigate the mental and social health in the old age population during COVID-19 lockdown in Germany. Moreover, we aimed to inspect associations of mental and social health with sociodemographic factors, aspects of the personal life situation during lockdown and attitudes towards COVID-19 as well as resilience.

\section{Methods}

Study design and sample

The survey was conducted as a computer-assisted telephone interview by USUMA, a leading social research institute in Germany. The target sample size was 1,000 individuals at least 65 years old. Sampling was based on multi-stage random digital dialing, drawing from 
the Association of German Market and Social Research Agency's (ADM) sample base that includes registered and non-registered telephone numbers. Telephone numbers were drawn proportionally to the German population structure and regionally stratified according to district sizes throughout Germany. This would ensure a random selection of households. Within households, the target person to be interviewed was randomly selected if there was more than one individual being 65 years and older, applying the Kish-Selection-Grid [11]. All interviewers were trained to conduct interviews. Data were collected from April $6^{\text {th }}$ to April $25^{\text {th }}, 2020$, when nationwide COVID-19 lockdowns were continuously in force.

\section{Assessments}

The structured telephone interview consisted of three parts. First, sociodemographic data were collected, which comprised standardized questions on age (years), gender (self-report; female/male/other), educational attainment (highest school degree), occupational attainment (highest occupational degree/training), marital status (married, single, divorced, widowed) and living situation (alone, with partner/spouse, with relatives others than partner/spouse, with others).

Second, participants were asked eleven questions in direct relation to the COVID-19 pandemic, comprising attitudes to and compliance with mass quarantine measures, exposure to COVID-19 and perceived barriers in daily life. Six 5-point Likert-scale items („totally disagree“ to „totally agree“) were used to assess the extent of being worried about COVID-19, perceived threat by COVID-19, perceived threat by COVID-19 due to age, perceived threat by COVID-19 due to pre-existing health conditions, support of the governmental measures to curb the virus spread, and perceived restriction by the governmental measures. Moreover, we asked participants whether they or someone they knew were infected and/or in self-isolation due to exposure to the virus. Frequencies of direct and indirect contact with individuals outside of the household over the past week were assessed, respectively („,no contact at all“ to „several times a day“). Finally, we asked whether participants received support in everyday tasks and whether access to medical health care services was unaltered (yes/no/partially). 
The third part of the interview comprised short standardized screening instruments for mental and social health variables. We provide a description of each instrument below.

The Brief Symptom Inventory (BSI-18) was used to assess depression, anxiety and somatization as well as a global indicator of psychological distress, the Global Severity Index (GSI; including all 18 items) [12]. Questions apply to the past week and are answered using a 5-point Likert-scale („not at all“ to „very much“). Results are presented as mean scores. Good evidence has been reported on the psychometric properties of the German version of the BSI-18 [12].

Posttraumatic stress was assessed using the Posttraumatic Stress Scale (PTSS-10) [13]. The scale comprises ten self-report items measuring the presence and intensity of ten posttraumatic stress symptoms (e.g. irritability, withdrawal) over the past seven days using a 7-point Likert-scale ("never" to "always"). Scores (range: 10-70) are summed; 23-35 indicates increased posttraumatic stress; $\geq 36$ indicates a probable posttraumatic stress disorder (PTSD) (Stoll et al., 1999). Good internal consistency has been reported for the PTSS-10 (Cronbach's $\alpha=0.85)[13]$.

Perceived stress was assessed using the 4-item short version of the Perceived Stress Scale (PSS4) [14]. A 5-point Likert-scale ranges from „never“ to „very often“. Higher scores (range: 0-16) indicate higher perceived stress. The short version was considered well suited for assessing perceived stress in interviews with limited time [15].

To measure loneliness, we applied the 3-item version of the University of California, Los Angeles Loneliness Scale (UCLA-3) [16]. The questions elicit information on the subjective perception of social isolation („often“, „sometimes“, „seldom“ and „never“; scored 0 to 3). Scores are summed; a score $\geq 6$ indicates loneliness. The UCLA-3 is a reliable and valid measure for loneliness, specifically in telephone interviews [17].

The ENRICHD Social Support Inventory (ESSI) served to measure perceived social support [18]. It comprises five items with 5-point Likert-scale response options ("never" to "always") asking e.g. about the availability of advice or affection from close others. Scores are summed up (range: $5-25$ ), a cut-off $\leq 18$ and having scored $\leq 3$ on at least two items 
indicates low social support. The German version of the ESSI has been validated, showing good psychometric properties [19].

We measured resilience, i.e. the capability to rally from stress, using the Brief Resilience Scale (BRS) [20]. The BRS consists of 6 items that are either positively or negatively worded, reducing response bias in relation to social desirability. Answers are recorded on a 5-point Likert-scale („totally disagree“ to „totally agree“). The mean score of all item responses is used to quantify resilience (range: 1-5). A higher mean score indicates higher resilience. It can be classified in 1.00-2.99 = low resilience, 3.00-4.30 = normal resilience, $4.31-5.00=$ high resilience. The validated German adaptation was used [21].

Lastly, as an indicator of social isolation, we used information on household composition and the frequency of contact with others. Therefore, we would consider everyone being socially isolated, who would a) live alone, b) have no direct contacts and c) have a maximum of indirect contact with others of 3 to 4 times a week over the past week.

\section{Data analysis}

The sample was weighted to account for differential sampling probabilities based on age, gender and region across Germany using census data. T-tests and Chi-square tests were used to inspect whether other socio-demographic characteristics differed by gender. These procedures were also applied in regard to aspects of the personal life situation during lockdown and attitudes towards COVID-19 as well as variables of mental and social health. Subsequently, multiple multivariate regression models were fitted to examine associations between sociodemographic factors, aspects of personal life situation during lockdown, attitudes towards COVID-19 and resilience, on the one hand, and mental and social health variables, on the other. We used continuous sum or mean scores of mental and social health outcomes, as appropriate, thus applying linear regression models; except for social isolation, which was a binary outcome and thus logistic regression was applied. Adjusted models included continuous independent variables, except for: gender (dichotomous; female in reference to male), education (categorical; categorized according to the Comparative Analysis of Social Mobility in Industrial Nations/CASMIN classification; low, middle in 
reference to high [22]), living alone (dichotomous; living alone in reference to cohabiting), receiving support in everyday tasks over the past weeks (categorical; no, partially in reference to yes), unchanged access of health services (categorical; no, partially in reference to yes), COVID-19 infection (categorical; self, household/family member in reference to no infection), self-isolation due to SARS-CoV-2 exposure (categorical; self, household/family member in reference to not applicable), being supportive of the government's quarantine measures (dichotomous; due to invariance in response to the 5-point Likert-scale responses were collapsed into a dichotomous outcome: no in reference to yes). We furthermore repeated all models without adjusting for resilience in order to inspect the potential impact of this covariate. We report standardized beta $(\beta)$ coefficients to allow for direct comparisons between dependent variables as well as between outcomes; except for the binary outcome social isolation (odds ratios/OR). Analyses were conducted using STATA 16.0 SE (College Station, Texas, USA), assuming a statistical significance level of $p \leq .05$.

\section{Results}

Sample

The sample consisted of 1,005 individuals aged 65 years and older. Initially, 1,863 individuals were randomly selected. Of these, $10.7 \%(n=200)$ refused to participate and $35.3 \%(n=658)$ of the selected households could not be reached, leading to a response rate of $54.0 \%$.

Participants were on average $75.5(S D=7.1$; range $=65-94)$ years old; $56.3 \%$ were women. Compared to men, women were slightly older $(M=74.8, S D=6.8$ vs. $M=76.0, S D$ $=7.3 ; t(1)=-2.67, p=.008$ ), less educated (high education: $49.2 \%$ vs. $26.1 \% ; p<.001$ ), less often married $\left(71.5 \%\right.$ vs. $\left.43.9 \% ; X^{2}(2)=59.44, p<.001\right)$ and more often living alone $(25.9 \%$ vs. $\left.40.5 \% ; X^{2}(1)=23.36, p<.001\right)($ Table 1$)$. 
Aspects of the personal life situation during COVID-19 lockdown

At the time of data collection, COVID-19 lockdown had continuously been in force for an average of 28 days $(S D=4.8)$. Two study participants $(0.2 \%)$ reported having been infected with COVID-19 and less than every fifth respondent reported knowing about a case in their close or extended social network $(n=174 ; 17.2 \%)$. Self-isolation due to potential exposure to COVID-19 was reported by 12 participants (1.2\%), while they knew of 157 (15.3\%) individuals in their close or extended social network who had to self-isolate. As for frequency of social contact, $42.7 \%(n=430)$ of the participants did not have any direct contact with others outside of their household during lockdown; however, more than half of the respondents ( $n=507,50.4 \%$ ) reported having had indirect contact with persons outside their household every day or several times a day. The majority received at least partial support in carrying out everyday tasks (e.g. buying groceries) ( $n=896 ; 90.0 \%)$ and was at least partially able to access health care services as usual $(n=823 ; 81.9 \%)$. More results are detailed in Table 2.

- insert Table 2 -

Attitudes towards COVID-19 and associated measures

More than half of the respondents $(n=521 ; 53.6 \%)$ stated to worry about COVID-19, more than one-third of them to do so strongly ( $n=346 ; 36.2 \%)$. About one-third $(n=360 ; 35.8 \%)$ stated to feel threatened by COVID-19, about one quarter of them to feel so strongly ( $n=$ $233 ; 23.2 \%)$. More than half of the respondents stated that the perceived threat was due to their advanced age $(n=547 ; 54.4 \%)$, with 391 (38.9\%) agreeing strongly with this statement. About one-third felt threatened due to pre-existing health conditions ( $n=370 ; 36.9 \%), 279$ $(27.8 \%)$ felt so strongly. The vast majority $(n=903 ; 89.8 \%)$ was supportive of the governmental quarantine measures, with most participants agreeing strongly with them ( $n$ $=784 ; 78.0 \%)$. More than a quarter felt restricted by the quarantine measures $(n=277$; $27.6 \%), 152(15.1 \%)$ of them strongly. Over $40 \%(n=416)$ did not feel restricted during lockdown. There were no significant gender differences in regard to attitudes to COVID-19, 
except for women feeling a significantly greater threat by COVID-19 due to their age compared to men $\left(42.5 \%\right.$ vs. $\left.35.2 \% ; X^{2}(4)=13.90, p=.008\right)$. Figure 1 illustrates the response distributions in regard to attitudes. Further results are detailed in Table 2.

\section{- insert Figure 1-}

\section{Mental and social health during COVID-19 lockdown}

Table 3 provides mean scores and prevalence estimates of the mental and social health of older individuals during COVID-19 lockdown. Women had significantly higher scores and a higher prevalence of all mental and social health outcomes than men, except for perceived stress and social support, which both did not differ between genders. Two-thirds ( $n=645$; $67.5 \%)$ of all participants reported moderate resilience, $13.8 \%(n=132)$ had low resilience and $18.6 \%(n=178)$ high resilience. Overall, women had slightly lower resilience compared to men $(M=3.5, S D=0.7$ vs. $M=3.7, S D=0.7 ; t(1)=3.69, p<.001)$.

\section{- insert Table 3 -}

Associations of sociodemographic factors and mental and social health during COVID-19 lockdown

Results of this and all following sections are detailed in Table 4. Higher age was associated with increased somatization $(\beta=.16 ; p=.002)$, overall psychological distress (GSI; $\beta=.10 ; p$ $=.047)$, perceived stress $(\beta=.09 ; p=.044)$ and social isolation $(\mathrm{OR}=1.06,95 \% \mathrm{Cl}=1.02-$ $1.11 ; p=.006)$. Posttraumatic stress symptoms $(\beta=.11 ; p=.004)$, loneliness $(\beta=.11 ; p=$ $.004)$ and social isolation $(\mathrm{OR}=1.60,95 \% \mathrm{Cl}=1.06-2.35 ; p=.025)$ were more pronounced in women than in men. Compared to participants with high education, those with low education $(\beta=.14 ; p<.001)$ and middle education $(\beta=.14 ; p<.001)$ reported increased perceived stress and, in addition, those with low education $(\mathrm{OR}=1.99,95 \% \mathrm{Cl}=1.19-2.35 ; p$ $=.009$ ) increased social isolation. Finally, we observed less perceived social support in participants living alone $(\beta=-.16 ; p=.008)$ compared to those cohabiting. 
- insert Table 4 -

Associations of aspects of the personal life situation and mental and social health during COVID-19 lockdown

Duration of lockdown was not significantly associated with mental or social health. Moreover, frequency of being directly or indirectly in contact with other persons outside of the own household was not significantly associated with any outcome, except for having more frequent indirect contact, which was associated with higher perceived social support $(\beta=.13$; $p<.001)$. Receiving no support $(\beta=.11 ; p=.006)$ or only partial support $(\beta=.10 ; p=.01)$ in taking care of daily activities (e.g. buying groceries) was associated with increased perceived stress compared to having such support. Partially reduced access to health services was associated with overall psychological distress (GSI; $\beta=.07 ; p=.023)$ in reference to unchanged access to health services; however, there was no association with more than partially changed access to health services use $(\beta=.03 ; p=.499)$. Being infected with COVID-19 was associated with increased somatization $(\beta=.03 ; p=.028)$; however, there were only 2 cases in the sample. Having to self-isolate due to exposure to COVID-19 was associated with loneliness $(\beta=-.07 ; p=.008)$.

Associations of attitudes towards COVID-19 and mental and social health variables during COVID-19 lockdown

Worry about COVID-19 was associated with increased depressive symptoms $(\beta=.08 ; p=$ $.038)$, anxiety $(\beta=.20 ; p=.012)$, perceived stress $(\beta=.12 ; p=.003)$ and a lower likelihood of being socially isolated $(\mathrm{OR}=0.80,95 \% \mathrm{Cl}=0.67-0.96 ; p=.018)$. There were no associations with perceived threat by COVID-19 in general or due to age specifically; however, perceived threat by COVID-19 due to pre-existing health conditions was associated with increased somatization $(\beta=.20 ; p<.001)$ and overall psychological distress (GSI; $\beta=$ $.11 ; p=.004)$. Not being supportive of the lockdown was associated with increased somatization ( $\beta=.06 ; p=.033$ ), overall psychological distress (GSI; $\beta=.07 ; p=.038$ ) and perceived stress $(\beta=.07 ; p=.040)$. Lastly, feeling more restricted by the lockdown was 
associated with increased depression $(\beta=.11 ; p<.001)$ and overall psychological distress $(\mathrm{GSI} ; \beta=.60 ; p=.048)$.

Resilience in regard to mental and social health during COVID-19 lockdown Resilience was strongly associated with better mental and social health, except for social isolation. Higher resilience indicated less depressive symptoms $(B=-.32 ; p<.001)$, anxiety $(B=-.35 ; p<.001)$, somatization $(B=-.23 ; p<.001)$, overall psychological distress (GSI; $B=$ $-.35 ; p<.001)$, posttraumatic stress $(B=-.36 ; p<.001)$, perceived stress $(B=-.30 ; p<.001)$ loneliness $(B=-.15 ; p<.001)$ and higher social support $(B=.08 ; p=.021)$. Resilience significantly added to the explained variance in all models, which is apparent through comparisons with models that did not control for resilience (see additional Table S1).

\section{Discussion}

We provide results of a representative cross-sectional survey on the mental and social health in the old age population ( $\geq 65$ years) during COVID-19 lockdown in Germany with respect to sociodemographic factors, aspects of the personal life situation during lockdown and attitudes towards COVID-19. Results reflect a snapshot after lockdown had continuously been in force in Germany for an average of 28 days in April 2020.

Overall, mean scores and prevalence of mental and social health did not differ markedly from those reported before the pandemic. In detail, normative values for the mean BSI-18 scores [23] measuring depression, anxiety, somatization and overall psychological stress (GSI) in German individuals aged 60-95 years (mean age: 70.8 years) compared to our results were: 2.0 vs. $1.4,1.6$ vs. $1.6,2.4$ vs. 2.2 and 6.0 vs. 5.1 , respectively, indicating similar or even lower figures in our sample. The prevalence of probable PTSD (2.1\%) and the proportion of individuals with increased posttraumatic stress $(9.8 \%)$ in our sample were in the range of numbers reported in previous representative population-based surveys among German elderly, which found a one-month prevalence of $3.4 \%$ (age: $\geq 60$ years) and $4.0 \%$ (age: $60-85$ years), respectively, and a proportion of $3.8 \%$ and $12.2 \%$, respectively, who fulfilled the criteria of partial PTSD $[24,25]$. Though instruments and diagnostic criteria 
differed between studies and our sample was slightly older ( $\geq 65$ years), overall, prevalence of posttraumatic stress was comparable and did not seem to have increased during COVID19 lockdown. However, this outcome needs longitudinal observation as posttraumatic stress may rather develop in the aftermath of the pandemic.

We could not find normative values for scores of the PSS-4, measuring perceived stress, based on German old age samples. However, mean normative scores in individuals above 65 years of age in an English sample were $5.3(S D=2.9)$ and $4.9(S D=2.9)$ in a Spanish sample $[15,26]$. In comparison, perceived stress $(M=6.0, S D=2.5)$ may have been slightly higher in the German old age population during COVID-19 lockdown; however this interpretation should be viewed with caution.

Estimates of social isolation prevalence typically vary and are difficult to compare across studies due to a lack of commonly used standardized instruments [27]. Likewise, in our survey, we used indicators (living alone, having no direct contacts and a maximum of indirect contact with others 3 to 4 times a week over the past week) to estimate social isolation, which resulted in a prevalence of $13.2 \%$. Compared to other studies, this did not hint to increased social isolation during COVID-19 lockdown. For example, social isolation prevalence in a representative sample aged $60-79$ year was $21.2 \%$ [28], in communitydwelling older adults aged $65-90$ years $18.4 \%$ [29], and in a cross-sample comparison of individuals aged 65 years and older in Hamburg, Germany, Solothurn, Swiss and London, UK, social isolation prevalence ranged from $11 \%$ to $20 \%$ [30].

Similar to social isolation, there is variability in loneliness measurement, challenging comparisons. In a random German sample aged 64-94 years using the 12-item version of the UCLA loneliness scale, the frequency of loneliness was $19 \%$ in men and $22 \%$ in women, respectively [31]. In the cross-national Survey of Health, Ageing and Retirement in Europe (SHARE; age: $\geq 65$ years), $13.7 \%$ of the German participants stated to feel lonely most of the time [32], and in the European Social Survey, $7 \%$ of the Germans aged 60 years and older reported being lonely [33]. As loneliness prevalence in our sample (total: 13.1\%; men: 8.8\%, women: $16.3 \%$ ) fell within the range of estimates reported before the pandemic, this did not 
suggest an increase in loneliness during COVID-19 lockdown; notably though, women's loneliness was almost as double as high as men's.

Drawing on German normative values for the ESSI, our results indicated slightly higher perceived social support during COVID-19 lockdown. The median ESSI score was 22.0 for women and 23.0 for men, indicating $50 \%$ of the participants in our sample scored 22 points or less on the ESSI. These scores equal $73.0 \%$ of women and $71.1 \%$ of men aged $64-99$ years according to the normative percentile ranks [19].

Likewise, mean resilience scores (BRS) were slightly above norms for the German old population above 60 years of age. The median BRS score was 3.5, indicating $50 \%$ of our study population had this or a lower score, compared to $53.2 \%$ or more in the normative population [34]. Gender differences in mean scores and prevalence of mental and social health were typical, with women mostly yielding higher figures than men.

There were only few aspects of the personal life situation during COVID-19 lockdown that were associated with mental and social health variables. E.g., a higher indirect contact frequency with persons outside of the household was associated with higher perceived social support, whereas not or only partially receiving social support was associated with higher perceived stress. Experiencing partially changed access to health care services was associated with higher global psychological distress (GSI). These results may point to psychological effects of the COVID-19 lockdown in certain subgroups.

On average, older individuals expressed worry about COVID-19, but they were understanding and supportive of the COVID-19 lockdown. There were only few associations of attitudes towards COVID-19 and mental and social health. Notably, being worried about COVID-19 was associated with higher depressive symptoms, anxiety and perceived stress. A perceived threat by COVID-19 due to pre-existing health conditions was associated with higher somatization and global psychological distress. Though almost $90 \%$ stated to support the lockdown, not being supportive was associated with higher somatization, overall psychological distress as well as perceived stress; potentially in this group, individuals were in favor of even more comprehensive quarantine measures to slow the spread of the virus. In contrast, those feeling more restricted by the COVID-19 lockdown showed higher depressive 
symptoms. Overall, most life aspects and attitudes did not show associations with mental and social health, suggesting that the old age population in Germany was dealing rather well with the crisis four weeks into lockdown.

In fact, looking at the results synoptically, we argue that, overall, the mental and social health of the German old age population was largely unaltered during COVID-19 lockdown. However, the few significant associations point to a differential impact of the COVID-19 lockdown, implying that certain groups of older individuals may have had more difficulties to adjust to the situation; these could comprise, e.g. individuals with pre-existing health conditions, individuals with certain personality traits, those with small social networks or those with increased medical or care needs [35]. This requires further investigation and is beyond the scope of this work. Notably, resilience was strongly associated with all mental and social health variables, except for social isolation, which explained a large amount of variance and attenuated the associations discussed above. It implies that, on average, older individuals are resilient against disruptive life events, probably because of having mastered crises throughout life. Other studies on the mental and social health of older adults during COVID-19 lockdowns draw similar conclusions [5, 36, 37]. E.g., Lopez et al. [36] suggested, based on a study of 60-80 year old Spaniards, the COVID-19 impact may not be as relevant for the older adults' well-being as their appraisals and resources for managing COVID-19related problems. Plomecka et al. [5] reported overall lower psychological distress with increasing age, being markedly lower in older age groups, across 12 countries. Thyrian et al. [37] surveyed a convenience sample of older German individuals with cognitive impairment, finding a limited impact of the pandemic on psychological variables including depression, anxiety and loneliness in the short-term. These results, in line with ours, refute the public perception of the "weak and vulnerable elderly", which has sparked debates and a new rise in ageism over the course of the pandemic $[9,10]$. However, these results mostly stem from high-income countries. The impact of COVID-19 lockdowns on the mental and social health of older individuals likely varies considerably between countries, whereby country income level, living conditions, the extent of the outbreak (number of COVID-19 infections, number of deaths), governmental management of the crisis, health care infrastructure and responses of 
the public health system are important influential factors. E.g., a study from the Philippines (a lower-middle income country) concluded that older Filipinos suffered emotionally, spiritually and socially with the country not being sufficiently equipped to manage the crisis [38]. Similar concerns have been expressed from India [39]. This requires differentiated considerations and targeted and tailored measures in the area of public health.

\section{Strengths and limitations}

A strength of the study is the representative design and the timely data collection period during COVID-19 lockdown in April 2020 in Germany, thereby capturing the immediate impact of the pandemic. A limitation is the cross-sectional design, which only allowed for comparisons of outcomes with previous studies. Such comparisons are challenging due to sample deviations or different measurements. However, we were able to draw on normative data for a range of outcomes. Furthermore, due to time restrictions during telephone interviews, we were not able to consider other relevant factors that may be associated with the mental and social health of older individuals during the COVID-19 lockdown, for example, specific pre-exiting physical or psychiatric conditions.

\section{Conclusions}

Overall, the mental and social health of the old age population in Germany was largely unaltered during COVID-19 lockdown. There was evidence for worry about COVID-19 and increased perceived stress, but in general, the elderly felt socially supported and showed acceptance of and resilience against the challenging pandemic conditions. This does not preclude that certain subgroups are not able to deal well with the crisis and are indeed in need for mental health care. Therefore, further differential analyses as well as longitudinal monitoring of the mental and social health of the elderly over the course of the pandemic and post-pandemic are necessary to provide robust evidence and to understand long-term effects of the COVID-19 pandemic. 


\section{List of abbreviations}

95\%Cl: 95\% confidence interval

ADM: Association of German Market and Social Research Agency's

BRS: Brief Resilience Scale

BSI-18: Brief Symptom Inventory - 18 items

CASMIN: Comparative Analysis of Social Mobility in Industrial Nations

COVID-19: Corona Virus Disease 2019

ENRICHD: Enhancing Recovery in Coronary Heart Disease

ESSI: ENRICHD Social Support Inventory

GSI: Global Severity Index

OR: Odds ratio

PSS: Posttraumatic stress

PTSD: Posttraumatic stress disorder

PTSS-10: Posttraumatic Stress Scale - 10 items

SARS-CoV-2: Severe Acute Respiratory Syndrome Coronavirus 2

SD: Standard deviation

UCLA: University of California, Los Angeles

USA: United States of America

WHO: World Health Organization

\section{Declarations}

Ethics approval and consent to participate

This study was performed in line with the principles of the Declaration of Helsinki, revised version from 2000. The Ethics Committee of the Medical Faculty of the University of Leipzig approved this study (Ref: 137/20-ek). Participants were verbally informed about the study at the beginning of the telephone interviews, and then asked to consent, documented by USUMA. 


\section{Consent for publication}

Not applicable.

Availability of data and materials

Data are available to researchers upon reasonable request to the corresponding author.

\section{Competing interests}

None.

\section{Funding}

This work was supported by the Hans and Ilse Breuer Foundation.

\section{Authors' contributions}

SR and SRH designed the study, supervised the data collection, analyzed the data and wrote the article. UR revised the article for important intellectual content. All authors agree with the findings and the final version of the article.

\section{Acknowledgments}

We thank Felix Müller, Rosa Siemensmeyer and Felix Wittmann for writing assistance. 


\section{References}

1. Hui DS, I Azhar E, Madani TA, Ntoumi F, Kock R, Dar O, et al. The continuing 2019-nCoV epidemic threat of novel coronaviruses to global health - The latest 2019 novel coronavirus outbreak in Wuhan, China. Int J Infect Dis. 2020;91:264-6.

2. Robert Koch-Institute: Täglicher Lagebericht des RKI zur Coronavirus-Krankheit-2019 (COVID-19) 31.05.2020 - Aktualisierter Stand für Deutschland. https://www.rki.de/DE/Content/InfAZ/N/Neuartiges_Coronavirus/Situationsberichte/202005-31-de.pdf?_blob=publicationFile (2020). Accessed 7 Jun 2020.

3. World Health Organization: Mental health and psychosocial considerations during the COVID-19 outbreak. https://www.who.int/docs/default-source/coronaviruse/mentalhealth-considerations.pdf?sfvrsn=6d3578af_10 (2020). Accessed 15 May 2020.

4. Röhr S, Müller F, Jung F, Apfelbacher C, Seidler A, Riedel-Heller SG. Psychosoziale Folgen von Quarantänemaßnahmen bei schwerwiegenden CoronavirusAusbrüchen: ein Rapid Review [Psychosocial Impact of Quarantine Measures During Serious Coronavirus Outbreaks: A Rapid Review]. Psychiatr Prax. 2020;47(4):179-89.

5. Plomecka MB, Gobbi S, Neckels R, Radziński P, Skórko B, Lazerri S et al. Mental Health Impact of COVID-19: A global study of risk and resilience factors. medRxiv. 2020; doi: 2020.05.05.20092023.

6. Holt-Lunstad J, Smith TB, Baker M, Harris T, Stephenson D. Loneliness and social isolation as risk factors for mortality: a meta-analytic review. Perspect Psychol Sci. 2015;10(2):227-37.

7. Röhr S, Löbner M, Gühne U, Heser K, Kleineidam L, Pentzek M et al. Changes in social network size are associated with cognitive changes in the oldest-old. Frontiers in Psychiatry. 2020;11:330.

8. Hardy SE, Concato J, Gill TM. Resilience of community-dwelling older persons. J Aa Geriatr Soc. 2004;52(2):257-62.

9. Brooke J, Jackson D. Older people and COVID-19: Isolation, risk and ageism. J Clin Nurs. 2020;29(13-14):2044-46. 
10. Fraser S, Lagacé M, Bongué B, Ndeye N, Guyot J, Bechard L et al. Ageism and COVID19: What does our society's response say about us? Age Ageing. 2020:afaa097.

11. Kish L. A Procedure for Objective Respondent Selection within the Household. J Am Stat Assoc. 1949;44:380-7.

12. Spitzer C, Hammer S, Löwe B, Grabe HJ, Barnow S, Rose M et al. Die Kurzform des Brief Symptom Inventory (BSI -18): erste Befunde zu den psychometrischen Kennwerten der deutschen Version [The short version of the Brief Symptom Inventory (BSI -18): preliminary psychometric properties of the German translation]. Fortschr Neurol Psychiatr. $2011 ; 79(9): 517-23$.

13. Maercker A. Posttraumatische-Stress-Skala-10 (PTSS-10). In: Hoyer J, Margraf J, editors. Angstdiagnostik - Grundlagen und Testverfahren. Berlin: Springer; 2003. p. 401-403.

14. Cohen S, Kamarck T, Mermelstein R. A global measure of perceived stress. Journal of Health and Social Behavior. 1983;24:385-96.

15. Warttig SL, Forshaw MJ, South J, White AK. New, normative, English-sample data for the short form perceived stress scale (PSS-4). J Health Psychol. 2013;18(12):1617-28.

16. Russell D, Peplau LA, Cutrona CE. The revised UCLA Loneliness Scale: concurrent and discriminant validity evidence. J Pers Soc Psychol. 1980;39(3):472.

17. Hughes ME, Waite LJ, Hawkley LC, Cacioppo JT. A short scale for measuring loneliness in large surveys: Results from two population-based studies. Res Aging. 2004;26(6): 65572.

18. ENRICHD. Enhancing Recovery in Coronary Heart Disease (ENRICHD) study intervention: rationale and design. Psychosom Med. 2001;63:747-55.

19. Cordes A, Herrmann-Lingen C, Büchner B, Hessel A. Repräsentative Normierung des ENRICHD-Social-Support-Instrument (ESSI)-Deutsche Version. Klin Diag Eva. 2009;2(1):16-32.

20. Smith BW, Dalen J, Wiggins K, Tooley E, Paulette C, Bernard J. The brief resilience scale: assessing the ability to bounce back. Int J Behav Med. 2008;15(3):194-200. 
21. Chmitorz A, Wenzel M, Stieglitz RD, Kunzler A, Bagusat C, Helmreich I. Population-based validation of a German version of the Brief Resilience Scale. PLoS One. 2018;13(2):e0192761.

22. Brauns $\mathrm{H}$, Scherer S, Steinmann S. The CASMIN educational classification in international comparative research. In: Hoffmeyer-Zlotnik JHP, Wolf C, editors. Advances in Crossnational Comparison. Boston: Springer; 2003. p. 221-44.

23. Petrowski K, Schmalbach B, Jagla M, Franke GH, Brähler E. Norm values and psychometric properties of the brief symptom inventory-18 regarding individuals between the ages of 60 and 95. BMC Med Res Methodol. 2018;18(1):164.

24. Glaesmer H, Gunzelmann T, Braehler E, Forstmeier S, Maercker A. Traumatic experiences and post-traumatic stress disorder among elderly Germans: results of a representative population-based survey. Int Psychogeriatr. 2010;22:661-70.

25. Glaesmer H, Kaiser M, Braehler E, Freyberger HJ, Kuwert P. Posttraumatic stress disorder and its comorbidity with depression and somatisation in the elderly-A German community-based study. Aging Ment Health. 2012;16(4):403-12.

26. Vallejo MA, Vallejo-Slocker L, Fernández-Abascal EG, Mañanes G. Determining Factors for Stress Perception Assessed with the Perceived Stress Scale (PSS-4) in Spanish and Other European Samples. Front Psychol. 2018;9:37.

27. Hämmig O. Health risks associated with social isolation in general and in young, middle and old age. PLoS One. 2019;14(7):e0219663.

28. Rodriguez FS, Schroeter ML, Witte AV, Engel C, Löffler M, Thiery J et al. Could High Mental Demands at Work Offset the Adverse Association Between Social Isolation and Cognitive Functioning? Results of the Population-Based LIFE-Adult-Study. Am J Geriatr Psychiatry. 2017;25:1258-1269.

29. Herbolsheimer F, Mosler S, Peter R. Relationship Between Social Isolation and Indoor and Outdoor Physical Activity in Community-Dwelling Older Adults in Germany: Findings From the ActiFE Study. J Aging Phys Act. 2017;25:387-94. 
30. Lubben J, Blozik E, Gillmann G, lliffe S, von Renteln Kruse W, Beck JC et al. Performance of an Abbreviated Version of the Lubben Social Network Scale Among Three European Community-Dwelling Older Adult Populations. Gerontologist. 2006;46:503-13.

31. Zebhauser A, Hofmann-Xu L, Baumert J, Häfner S, Lacruz ME, Emeny RT. How much does it hurt to be lonely? Mental and physical differences between older men and women in the KORA-Age Study. Int J Geriatr Psychiatry. 2014;29(3):245-52.

32. Vozikaki M, Papadaki A, Linardakis M, Philalithis A. Loneliness among older European adults: results from Survey of Health, Aging and Retirement in Europe. J Public Health. 2018;26:613-24.

33. Yang K, Victor C. Age and loneliness in 25 European nations. Ageing Soc. $2011 ; 31(8): 1368-88$.

34. Kunzler, AM, Chmitorz A, Bagusat C, Kaluza AJ, Hoffmann I, Schäfer M. Construct Validity and Population-Based Norms of the German Brief Resilience Scale (BRS). Eur J Health Psychol. 2018;25(3):107-17.

35. Hwang T, Rabheru K, Peisah C, Reichman W, Ikeda M. Loneliness and social isolation during the COVID-19 pandemic. Int Psychogeriatr. 2020;1-4. Doi: 10.1017/S1041610220000988. [Epub ahead of print].

36. López J, Perez-Rojo G, Noriega C, Carretero I, Velasco C, Martinez-Huertas A. Psychological well-being among older adults during the COVID-19 outbreak: A comparative study of the young-old and the old-old adults. Int Psychogeriatr. 2020;1-6. doi:10.1017/S1041610220000964. [Epub ahead of print].

37. Thyrian JR, Kracht F, Nikelski A, Boekholt M, Schumacher-Schönert F, Rädke A. The situation of elderly with cognitive impairment living at home during lockdown in the Coronapandemic in Germany. Research Square. 2020; doi: 10.21203/rs.3.rs-38185/v1. [Preprint].

38. Buenaventura RD, Ho JB, Lapid MI. COVID-19 and mental health of older adults in the Philippines: a perspective from a developing country. Int Psychogeriatr. 2020;1-5. doi: 10.1017/S1041610220000757. [Epub ahead of print] 
39. Vahia V, Shah A. COVID-19 Pandemic and mental health care of older adults in India. Int Psychogeriatr. 2020;1-5. doi: 10.1017/S1041610220001441. [Epub ahead of print]. 
Table 1. Sociodemographic characteristics of the study sample $(n=1,005)$.

\begin{tabular}{|c|c|c|c|c|}
\hline & Total & $\begin{array}{l}\text { Women } \\
(n=566)\end{array}$ & $\begin{array}{c}\text { Men } \\
(n=439)\end{array}$ & $\begin{array}{c}\text { Group } \\
\text { difference } \\
\text { ( } p \text {-value) }\end{array}$ \\
\hline Age; $M, S D$, range & $75.50(7.11 ; 65-94)$ & $76.03(7.31)$ & $74.82(6.78)$ & .008 \\
\hline \multicolumn{5}{|l|}{ Education; $n, \%$} \\
\hline Low & $279(27.7)$ & $170(30.6)$ & 109 (24.9) & \\
\hline Middle & $352(35.1)$ & $240(43.2)$ & $113(25.9)$ & \\
\hline High & $360(35.9)$ & $145(26.1)$ & $215(49.2)$ & $<.001$ \\
\hline \multicolumn{5}{|l|}{ Marital status; $n, \%$} \\
\hline Married & $560(55.7)$ & 247 (43.9) & $313(71.5)$ & \\
\hline Single & $78(7.8)$ & $42(7.5)$ & $36(8.2)$ & \\
\hline Divorced & $100(9.9)$ & $70(12.4)$ & $30(6.8)$ & \\
\hline Widowed & $264(26.2)$ & $204(36.2)$ & $59(13.5)$ & $<.001$ \\
\hline \multicolumn{5}{|l|}{ Living situation; $n, \%$} \\
\hline Living alone & 341 (33.9) & $227(40.5)$ & $114(25.9)$ & \\
\hline Living with partner & $514(51.2)$ & $243(43.3)$ & $271(61.6)$ & \\
\hline Living with others & $146(14.5)$ & $91(16.2)$ & $55(12.5)$ & $<.001$ \\
\hline
\end{tabular}

Missing values: education: $n=13$ (1.3\%); marital status: $n=4(0.4 \%)$; living situation: $n=4(0.4 \%)$ 
Table 2. Aspects of the personal life situation and attitudes towards COVID-19 during lockdown in the old age population in Germany $(n=1,005)$.

\begin{tabular}{|c|c|c|c|c|}
\hline & Total & $\begin{array}{l}\text { Women } \\
(n=566)\end{array}$ & $\begin{array}{c}\text { Men } \\
(n=439)\end{array}$ & $\begin{array}{l}\text { Group difference } \\
\text { ( } p \text {-value) }\end{array}$ \\
\hline $\begin{array}{l}\text { Duration of quarantine measures; days } M \\
(S D ; \text { range) }\end{array}$ & $27.96(4.77,15-34)$ & $27.76(4.89)$ & $28.21(4.60)$ & .144 \\
\hline \multicolumn{5}{|l|}{ COVID-19 infection; $n$ (\%) } \\
\hline Self & $2(0.2)$ & $2(0.4)$ & $0(0.0)$ & \\
\hline Household members/family & $17(1.7)$ & $7(1.2)$ & $10(2.3)$ & \\
\hline Friends or neighbors & $44(4.4)$ & $17(3.0)$ & $27(6.1)$ & \\
\hline Others & $113(11.2)$ & $57(10.1)$ & $55(12.5)$ & .024 \\
\hline \multicolumn{5}{|l|}{ Isolation due to COVID-19 exposure; $n(\%)$} \\
\hline Self & $12(1.2)$ & $6(1.1)$ & $6(1.4)$ & \\
\hline Household members/family & $35(3.4)$ & $26(4.6)$ & $9(2.1)$ & \\
\hline Friends or neighbors & $52(5.2)$ & $23(4.1)$ & $29(6.6)$ & \\
\hline Others & $67(6.7)$ & $33(5.8)$ & $35(8.0)$ & .168 \\
\hline \multicolumn{5}{|l|}{$\begin{array}{l}\text { Frequency of direct contact with others } \\
\text { over past week; } n(\%)\end{array}$} \\
\hline Not at all & $430(42.7)$ & $251(44.3)$ & $179(40.7)$ & \\
\hline $1-2$ days & $292(29.1)$ & $166(29.3)$ & $126(28.6)$ & \\
\hline 3-4 days & $144(14.4)$ & $77(13.6)$ & $68(15.5)$ & \\
\hline 5-6 days & 40 (3.9) & $21(3.7)$ & $19(4.3)$ & \\
\hline Everyday & $66(6.6)$ & $34(6.0)$ & $32(7.3)$ & \\
\hline Several times everyday & $30(3.0)$ & $14(2.5)$ & $16(3.6)$ & .458 \\
\hline \multicolumn{5}{|l|}{$\begin{array}{l}\text { Frequency of indirect contact with others } \\
\text { over past week; } n(\%)\end{array}$} \\
\hline Not at all & $71(7.0)$ & $35(6.2)$ & $36(8.2)$ & \\
\hline 1-2 days & $130(12.9)$ & $57(10.1)$ & $73(16.6)$ & \\
\hline 3-4 days & $220(21.9)$ & $120(21.2)$ & $100(22.7)$ & \\
\hline $5-6$ days & $76(7.5)$ & $40(7.1)$ & $35(8.0)$ & \\
\hline Everyday & $340(33.8)$ & $208(36.8)$ & $133(30.2)$ & \\
\hline Several times everyday & $167(16.6)$ & $103(18.2)$ & $63(14.3)$ & .009 \\
\hline \multicolumn{5}{|l|}{ Receiving support in daily activities; $n(\%)$} \\
\hline Yes & $284(28.2)$ & $188(33.2)$ & 96 (21.9) & \\
\hline Partially & $612(60.8)$ & $78(13.8)$ & $31(7.1)$ & \\
\hline No & $110(10.9)$ & $300(53.0)$ & $312(71.1)$ & $<.001$ \\
\hline \multicolumn{5}{|l|}{ Unchanged health services access; $n$ (\%) } \\
\hline Yes & $607(60.4)$ & $316(55.8)$ & $291(66.1)$ & \\
\hline Partially & $216(21.5)$ & $99(17.5)$ & $63(14.3)$ & \\
\hline No & $162(16.1)$ & $138(24.4)$ & $79(18.0)$ & .010 \\
\hline \multicolumn{5}{|l|}{ Attitudes towards COVID-19 } \\
\hline \multicolumn{5}{|l|}{ Being worried about COVID-19; $n$ (\%) } \\
\hline Strongly disagree & $110(11.0)$ & $57(10.1)$ & $53(12.1)$ & \\
\hline Disagree & $129(12.9)$ & $68(12.0)$ & $62(14.1)$ & \\
\hline Neither agree nor disagree & $226(22.5)$ & $130(23.0)$ & 96 (21.9) & \\
\hline Agree & $175(17.4)$ & $92(16.3)$ & $82(18.7)$ & \\
\hline Strongly agree & $346(36.2)$ & $218(38.6)$ & $146(33.3)$ & .329 \\
\hline \multicolumn{5}{|l|}{ Perceived threat by COVID-19; $n$ (\%) } \\
\hline Strongly disagree & $148(14.7)$ & 84 (14.9) & $64(14.5)$ & \\
\hline Disagree & $207(20.6)$ & $1221(21.4)$ & $85(19.3)$ & \\
\hline Neither agree nor disagree & $289(28.8)$ & $165(29.2)$ & $125(28.4)$ & \\
\hline Agree & $127(12.6)$ & $59(10.4)$ & $68(15.5)$ & \\
\hline Strongly agree & $233(23.2)$ & $136(24.1)$ & $98(22.3)$ & .210 \\
\hline
\end{tabular}


Table 2 cont.

\begin{tabular}{|c|c|c|c|c|}
\hline & Total & $\begin{array}{l}\text { Women } \\
(n=566)\end{array}$ & $\begin{array}{c}\text { Men } \\
(n=439)\end{array}$ & $\begin{array}{l}\text { Group difference } \\
\text { ( } p \text {-value) }\end{array}$ \\
\hline \multicolumn{5}{|c|}{$\begin{array}{l}\text { Perceived threat by COVID-19 due to } \\
\text { age; } n(\%)\end{array}$} \\
\hline Strongly disagree & $90(9.0)$ & 50 (8.9) & $41(9.4)$ & \\
\hline Disagree & $135(13.5)$ & $79(14.1)$ & $56(12.9)$ & \\
\hline Neither agree nor disagree & $223(22.2)$ & $125(22.3)$ & $97(22.3)$ & \\
\hline Agree & $156(15.5)$ & $68(12.1)$ & $88(20.2)$ & \\
\hline Strongly agree & 391 (38.9) & $238(42.5)$ & $153(35.2)$ & .008 \\
\hline \multicolumn{5}{|c|}{$\begin{array}{l}\text { Perceived threat by COVID-19 due to } \\
\text { pre-existing health conditions; } n(\%)\end{array}$} \\
\hline Strongly disagree & $287(28.6)$ & $157(27.9)$ & $130(29.6)$ & \\
\hline Disagree & $164(16.3)$ & $91(16.2)$ & $73(16.6)$ & \\
\hline Neither agree nor disagree & 179 (17.9) & $107(19.0)$ & $72(16.4)$ & \\
\hline Agree & $91(9.1)$ & $51(9.1)$ & $41(9.3)$ & \\
\hline Strongly agree & $279(27.8)$ & $157(27.9)$ & $123(28.0)$ & .870 \\
\hline \multicolumn{5}{|c|}{$\begin{array}{l}\text { Being supportive of the government's } \\
\text { quarantine measures; } n(\%)\end{array}$} \\
\hline Strongly disagree & $8(0.8)$ & $5(0.9)$ & $3(0.7)$ & \\
\hline Disagree & $9(0.9)$ & $5(0.9)$ & $4(0.9)$ & \\
\hline Neither agree nor disagree & $81(8.0)$ & $42(7.4)$ & 39 (8.9) & \\
\hline Agree & $119(11.8)$ & $62(11.0)$ & $57(13.0)$ & \\
\hline Strongly agree & $784(78.0)$ & $450(79.8)$ & $334(76.4)$ & .733 \\
\hline \multicolumn{5}{|c|}{$\begin{array}{l}\text { Feeling restricted due to quarantine } \\
\text { measures; } n(\%)\end{array}$} \\
\hline Strongly disagree & $202(20.1)$ & $123(21.8)$ & 79 (18.0) & \\
\hline Disagree & $214(21.3)$ & $106(18.8)$ & $108(24.7)$ & \\
\hline Neither agree nor disagree & $310(30.8)$ & $183(32.4)$ & $127(29.0)$ & \\
\hline Agree & $125(12.5)$ & $64(11.3)$ & 61 (13.9) & \\
\hline Strongly agree & $152(15.1)$ & $88(15.6)$ & $63(14.4)$ & .084 \\
\hline
\end{tabular}

Missings: direct contact frequency: $n=3(0.3 \%)$; indirect contact frequency: $n=2(0.2 \%)$; unchanged medical services use: 20 (2.0\%); worry about COVID-19: $n=1(0.1 \%)$; threat by COVID-19: $n=1(0.1 \%)$; threat due to age: $n=11(1.1 \%)$; threat due to pre-existing health conditions: $n=4(0.4 \%)$; supportive of lockdown: $n=3(0.3 \%)$; perceived restriction: $n=2(0.2 \%)$ 
Table 3. Mental and social health in the old age population during COVID-19 lockdown in Germany $(n=1,005)$.

\begin{tabular}{|c|c|c|c|c|}
\hline & Total & $\begin{array}{l}\text { Women } \\
(n=566)\end{array}$ & $\begin{array}{c}\text { Men } \\
(n=439)\end{array}$ & $\begin{array}{c}\text { Group difference } \\
\text { ( } p \text {-value })\end{array}$ \\
\hline Depression; $M(S D)$ & $1.38(1.97)$ & $1.53(2.11)$ & $1.19(1.76)$ & .007 \\
\hline Anxiety; $M(S D)$ & $1.60(1.98)$ & $1.75(2.14)$ & $1.41(1.75)$ & .007 \\
\hline Somatization; $M(S D)$ & $2.16(2.77)$ & $2.32(2.92)$ & $1.95(2.53)$ & .036 \\
\hline Global severity index (GSI)*; $M(S D)$ & $5.13(5.49)$ & $5.59(5.87)$ & $4.55(4.89)$ & .003 \\
\hline \multicolumn{5}{|l|}{ Posttraumatic stress } \\
\hline$M(S D)$ & $11.00(9.30)$ & $12.33(9.78)$ & $9.28(8.33)$ & $<.001$ \\
\hline None; $n(\%)$ & $864(88.1)$ & $468(84.8)$ & $396(92.3)$ & \\
\hline Increased PTS; $n$ (\%) & $96(9.8)$ & $68(12.3)$ & $28(6.59$ & \\
\hline Probable PTSD; $n(\%)$ & $21(2.1)$ & $16(2.9)$ & $5(1.2)$ & $<.001$ \\
\hline Perceived stress; $M(S D)$ & $6.04(2.51)$ & $6.18(2.53)$ & $5.87(2.47)$ & .055 \\
\hline Social isolation; $n(\%)$ & $133(13.2)$ & $92(16.3)$ & $41(9.3)$ & $<.001$ \\
\hline \multicolumn{5}{|l|}{ Perceived social support } \\
\hline$M(S D)$ & $21.57(3.74)$ & $21.66(3.58)$ & 21.46 (3.93) & .421 \\
\hline High; $n(\%)$ & $820(83.1)$ & 464 (83.5) & $356(82.6)$ & \\
\hline Low; $n(\%)$ & 167 (16.9) & $92(16.5)$ & $75(17.4)$ & .722 \\
\hline \multicolumn{5}{|l|}{ Loneliness } \\
\hline$M(S D)$ & $4.13(1.36)$ & $4.30(1.48)$ & $3.91(1.17)$ & $<.001$ \\
\hline$n(\%)$ & $130(13.1)$ & $92(16.4)$ & $38(8.8)$ & $<.001$ \\
\hline \multicolumn{5}{|l|}{ Resilience } \\
\hline$M(S D)$ & $3.58(0.68)$ & $3.51(0.67)$ & $3.67(0.68)$ & $<.001$ \\
\hline High; $n(\%)$ & $178(18.6)$ & 90 (16.79) & $88(21.1)$ & \\
\hline Moderate; $n(\%)$ & $645(67.5)$ & $361(67.1)$ & $284(68.1)$ & \\
\hline Low; $n(\%)$ & $132(13.8)$ & $87(16.2)$ & $45(10.8)$ & .025 \\
\hline
\end{tabular}

*sum of depression, anxiety and somatization;

Abbreviations: $\mathrm{M}=$ mean; PTS = posttraumatic stress; PTSD = posttraumatic stress disorder SD = standard deviation; missings: depression: $n=14$ (1.4\%); anxiety: $n=17$ (1.7\%); somatization: $n=7$ (0.7\%); GSI: $n=30(3.0 \%)$; posttraumatic stress: $n=26(2.6 \%)$; perceived stress: $n=32(3.2 \%)$; perceived social support: $n=18(1.8 \%)$; loneliness: $n=11$ (1.1\%); resilience: $n=51$ (5.0\%) 


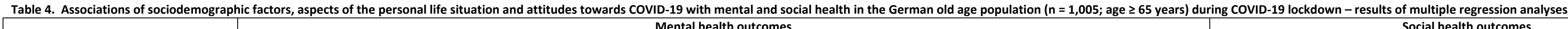

\begin{tabular}{|c|c|c|c|c|c|c|c|c|c|c|c|c|c|c|c|c|c|c|c|c|c|c|c|c|c|c|c|}
\hline \multirow{3}{*}{ (n) } & \multirow{2}{*}{\multicolumn{18}{|c|}{ Mental health outcomes }} & \multirow{2}{*}{\multicolumn{9}{|c|}{ Social health outcomes }} \\
\hline & \multicolumn{2}{|c|}{ Depressive symptoms } & & \multicolumn{3}{|c|}{ Anxiety } & \multicolumn{2}{|c|}{ Somatization } & & \multicolumn{3}{|c|}{ Global severity index ${ }^{\mathrm{f}}$} & \multicolumn{3}{|c|}{ Posttraumatic stress } & \multicolumn{3}{|c|}{ Perceived stress } & & & & & & & & & Social isolation \\
\hline & $\begin{array}{c} \\
\text { coef. }\end{array}$ & SE & $p$ & $\begin{array}{c}6 \\
\text { coef. }\end{array}$ & SE & $p$ & $\begin{array}{c} \\
\text { coef. }\end{array}$ & SE & $p$ & 8 coef. & SE & $p$ & 8 coef. & SE & $p$ & $\begin{array}{c}b \\
\text { coef. }\end{array}$ & SE & $p$ & \begin{tabular}{c|}
6 \\
coef.
\end{tabular} & SE & $p$ & \begin{tabular}{c|}
6 \\
coef.
\end{tabular} & SE & $p$ & OR & $95 \% \mathrm{Cl}$ & $p$ \\
\hline \multicolumn{28}{|l|}{ Sociodemographic factors } \\
\hline Age & .011 & .014 & .826 & .032 & .011 & .432 & .157 & .019 & .002 & .091 & .036 & .047 & .007 & .060 & .874 & .088 & .015 & .044 & -.063 & .024 & .179 & -.063 & .010 & .231 & 1.060 & $1.017-1.105$ & .006 \\
\hline Female gender (ref. male) & -.009 & .138 & .798 & .046 & .145 & .205 & .002 & .195 & .949 & .015 & .382 & .667 & .107 & .688 & .004 & -.024 & .181 & .513 & .045 & .277 & .226 & .110 & .106 & .004 & 1.596 & $1.061-2.399$ & .025 \\
\hline \multicolumn{28}{|l|}{ Education (ref. high) } \\
\hline Low & -.058 & .179 & 149 & -.009 & .176 & .814 & -.011 & .274 & .802 & -.031 & .503 & .440 & -.016 & .817 & .673 & 135 & .213 & $<.001$ & .018 & .342 & .663 & -.094 & .153 & .061 & 1.993 & $1.187-2.346$ & .009 \\
\hline Middle & -.066 & .190 & 147 & -.046 & .167 & .247 & -.043 & .259 & .336 & -.061 & .506 & .165 & -.005 & .826 & .905 & .141 & .220 & $<.001$ & .037 & .318 & .371 & -.082 & .157 & .136 & 1.552 & $0.923-2.610$ & .097 \\
\hline \multicolumn{28}{|l|}{ Marital status (ref. married) } \\
\hline Single & .085 & .367 & .085 & -.058 & 291 & .142 & -.035 & .415 & .388 & -.006 & .863 & .878 & .010 & 1.437 & .803 & .072 & .369 & .068 & -.174 & 677 & $<.001$ & .070 & .295 & .229 & & & \\
\hline Divorced & .068 & .272 & .094 & -.052 & .326 & .293 & -.018 & .572 & .774 & -.003 & 1.008 & .958 & -.030 & 1.745 & .595 & .030 & .469 & .591 & -.091 & .649 & .085 & .089 & .293 & .168 & $\mathrm{n} / \mathrm{a}$ & $n / a$ & $n / a$ \\
\hline Widowed & .175 & .341 & .020 & -.044 & .245 & .421 & .019 & .375 & .753 & .056 & .789 & .374 & -.011 & 1.249 & .847 & .044 & .330 & .456 & -.016 & .465 & .767 & .107 & .275 & .226 & & & \\
\hline Living alone (ref. cohabiting) & .059 & .320 & .435 & .058 & .231 & .296 & .062 & .388 & .351 & .069 & .788 & .305 & .062 & 1.217 & .316 & -.027 & .338 & .677 & -.161 & .476 & .008 & -.034 & .272 & .720 & $n / a$ & $\mathrm{n} / \mathrm{a}$ & $\mathrm{n} / \mathrm{a}$ \\
\hline Aspects of the personal life situation du & $\lg$ COVII & 19 lock & & & & & & & & & & & & & & & & & & & & & & & & & \\
\hline Duration of quarantine measures & -.021 & .018 & .628 & -.028 & .013 & .358 & -.047 & .022 & .208 & -.039 & .788 & .305 & .036 & .065 & .274 & -.018 & .019 & .620 & .002 & .026 & .955 & -.031 & .013 & .494 & 1.031 & $0.980-1.086$ & .234 \\
\hline $\begin{array}{l}\text { Frequency of direct contact with others } \\
\text { over past week }\end{array}$ & .048 & .027 & .239 & .033 & .020 & .268 & .039 & .029 & 211 & .050 & .072 & .202 & .017 & .058 & .346 & .027 & .013 & .074 & .010 & .022 & .565 & .021 & .013 & .454 & $n / a$ & $n / a$ & $n / a$ \\
\hline $\begin{array}{l}\text { Frequency of indirect contact with } \\
\text { others over past week }\end{array}$ & -.057 & .045 & .094 & -.043 & .047 & .237 & -.033 & .069 & .382 & -.047 & .134 & .202 & -.032 & .227 & .380 & -.007 & .067 & .857 & .133 & .095 & $<.001$ & .025 & .035 & .526 & $\mathrm{n} / \mathrm{a}$ & $n / a$ & n/a \\
\hline $\begin{array}{l}\text { Receiving support in daily activities (ref. } \\
\text { yes) }\end{array}$ & & & & & & & & & & & & & & & & & & & & & & & & & & & \\
\hline Some & .042 & .302 & .360 & .038 & .256 & .527 & -.015 & .375 & .708 & .011 & .705 & .771 & .020 & 1.143 & .596 & .102 & 299 & .010 & $\mathrm{n} / \mathrm{a}$ & $\mathrm{n} / \mathrm{a}$ & $\mathrm{n} / \mathrm{a}$ & -.020 & .165 & .587 & 1.117 & $0.490-2.548$ & .792 \\
\hline No & -.005 & .174 & .905 & .028 & .184 & .331 & -.081 & .246 & .058 & -.027 & .470 & .507 & -.013 & 0.798 & .761 & .112 & .223 & .006 & & & & .020 & .122 & .637 & 1.034 & $0.592-1.807$ & .906 \\
\hline $\begin{array}{l}\text { Unchanged health services access (ref. } \\
\text { ves) }\end{array}$ & & & & & & & & & & & & & & & & & & & & & & & & & & & \\
\hline Some & .044 & .170 & .530 & .056 & 187 & .113 & .064 & .267 & .075 & .073 & .480 & .023 & . 031 & .822 & .347 & -.029 & .221 & . 081 & -.022 & . 311 & .474 & . .006 & . 127 & .855 & 1.052 & $0.618-1.792$ & .940 \\
\hline No & .025 & .190 & .160 & -.033 & .166 & .339 & .046 & .262 & .241 & .025 & .494 & .499 & .007 & .825 & .847 & .067 & .231 & .385 & -.047 & .374 & .256 & .057 & .155 & .224 & 0.980 & $0.583-1.648$ & .851 \\
\hline COVID-19 infection (ref. not applicable) & & & & & & & & & & & & & & & & & & & & & & & & & & & \\
\hline Self & .013 & .856 & .569 & .061 & 1.827 & .201 & .032 & .774 & .028 & .042 & 3.268 & .173 & .061 & 9.386 & .242 & .012 & .673 & .397 & .003 & 1.710 & .909 & .063 & 2.024 & .411 & $n / a$ & n/a & $n / a$ \\
\hline Household/family member & .042 & .599 & .273 & .007 & .426 & .811 & .053 & .645 & .085 & .051 & 1.290 & .088 & -.015 & 1.617 & .511 & .060 & .699 & .110 & -.015 & .733 & .561 & .047 & .358 & .171 & 2.035 & $0.636-6.517$ & .231 \\
\hline Self-isolation (ref. not applicable) & & & & & & & & & & & & & & & & & & & & & & & & & & & \\
\hline Self & .003 & .549 & .912 & .013 & .379 & .541 & .042 & .547 & .059 & .027 & 1.040 & .211 & .023 & 2.121 & 368 & -.019 & .745 & .573 & .032 & .801 & 194 & -.065 & .317 & .008 & $\mathrm{n} / \mathrm{a}$ & & $n / a$ \\
\hline Household/family member & .003 & .378 & .936 & .000 & .349 & .988 & .018 & . 367 & .453 & .006 & .768 & .812 & .045 & 1.783 & .200 & $\begin{array}{r}-.044 \\
-.045-10\end{array}$ & .411 & .158 & .024 & .462 & .296 & 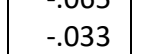 & .255 & .337 & 0.614 & $0.221-1.706$ & .349 \\
\hline Attitudes towards COVID-19 and associ & ed quara & tine me & sures & & & & & & & & & & & & & & & & & & & & & & & & \\
\hline Being worried & .076 & .054 & .038 & .096 & .056 & .012 & -.066 & .093 & .149 & .020 & .157 & .608 & .011 & .247 & .770 & .118 & .073 & .003 & .031 & .119 & .480 & .046 & .041 & .257 & 0.802 & $0.668-0.963$ & .018 \\
\hline Feeling threatened & .020 & .071 & .676 & .046 & .063 & .283 & .056 & .102 & .257 & .058 & .191 & .216 & .060 & .296 & .159 & .039 & .080 & .373 & .013 & .123 & .773 & -.005 & .056 & .925 & 0.913 & $0.749-1.113$ & .366 \\
\hline Feeling threatened due to age & -.002 & .070 & .972 & -.016 & .064 & .708 & -.004 & .091 & .933 & .000 & .175 & .999 & .037 & .300 & .394 & .008 & .083 & .854 & -.034 & .125 & .459 & .071 & .053 & .177 & 1.079 & $0.885-1.315$ & .452 \\
\hline $\begin{array}{l}\text { Feeling threatened due to pre-existing } \\
\text { health conditions }\end{array}$ & .020 & .048 & .609 & -.004 & .049 & .918 & .195 & .070 & $<.001$ & .106 & .127 & .004 & .056 & .218 & 131 & .049 & .061 & .210 & -.054 & .101 & .210 & -.005 & .056 & .925 & 1.034 & $0.880-1.214$ & .685 \\
\hline $\begin{array}{l}\text { Supportive of the government's } \\
\text { quarantine measures (ref. yes) }\end{array}$ & .056 & .226 & .098 & .031 & .206 & .321 & .063 & .274 & .033 & .065 & .577 & .038 & .062 & 1.013 & .056 & .069 & .279 & .040 & -.039 & .415 & .237 & .071 & .053 & .177 & 1.172 & $0.654-2.100$ & .594 \\
\hline $\begin{array}{l}\text { Feeling restricted due to quarantine } \\
\text { measures }\end{array}$ & .108 & .050 & $<.001$ & .061 & .050 & .066 & -.005 & .067 & .868 & .060 & .128 & .048 & .061 & .234 & .062 & .058 & .068 & .106 & -.010 & .101 & .776 & .002 & .037 & .956 & 1.117 & $0.933-1.337$ & .227 \\
\hline Resilience & -.316 & .017 & $<.001$ & -.347 & .016 & $<.001$ & -.229 & .023 & $<.001$ & -.352 & .044 & $<.001$ & -.360 & .075 & $<.001$ & -.300 & .023 & $<.001$ & .083 & .033 & .021 & -.146 & .013 & $<.001$ & 1.008 & $0.958-1.061$ & .751 \\
\hline Model aspects & & & & & & & & & & & & & & & & & & & & & & & & & & & \\
\hline Constant & 3.664 & 1.184 & .002 & 4.090 & 1.116 & $<.001$ & 1.067 & 1.528 & . 485 & 8.704 & 3.022 & .004 & 20.635 & 4.989 & $<.001$ & 5.308 & 1.449 & $<.001$ & 21.981 & 2.079 & $<.001$ & 5.277 & .779 & $<.001$ & 0.000 & $.000-.231$ & $<.001$ \\
\hline$R^{2}$ & & .237 & & & .192 & & & .213 & & & .263 & & & .226 & & & .228 & & & .154 & & & .109 & & & 072 & \\
\hline
\end{tabular}

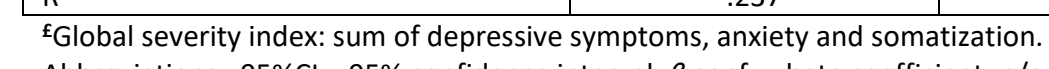

Abbreviations: $95 \% \mathrm{Cl}=95 \%$ confidence interval; $B$ coef. = beta coefficient; $\mathrm{n} / \mathrm{a}=$ not applicable; i.e. independent variable was not considered in the model due to collinearity; OR $=$ odds ratio; $p=p$-value; $S E=$ standard error 
Worry about COVID-19

Perceived threat by COVID-19

Perceived threat by COVID-19 due to age

Perceived threat by COVID-19 due to pre-existing health conditions Support of governmental measures to curb the spread of SARS-CoV-2

Perceived restriction by quarantine measures

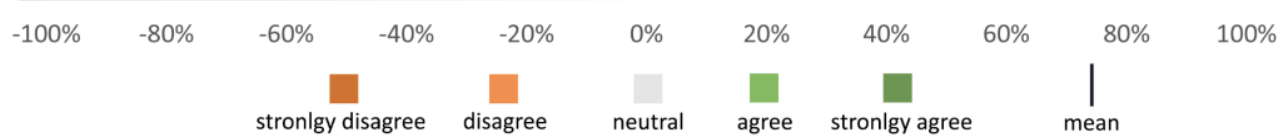

Figure 1. Attitudes of the old age population (representative sample: $65+$ years; $n=1,005$ ) in Germany in regard to COVID-19 and quarantine measures during COVID-19 lockdown in April 2020. 


\section{Appendix}

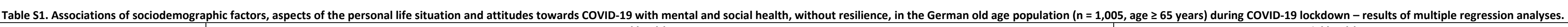
Mental health outcomes Social health outcomes

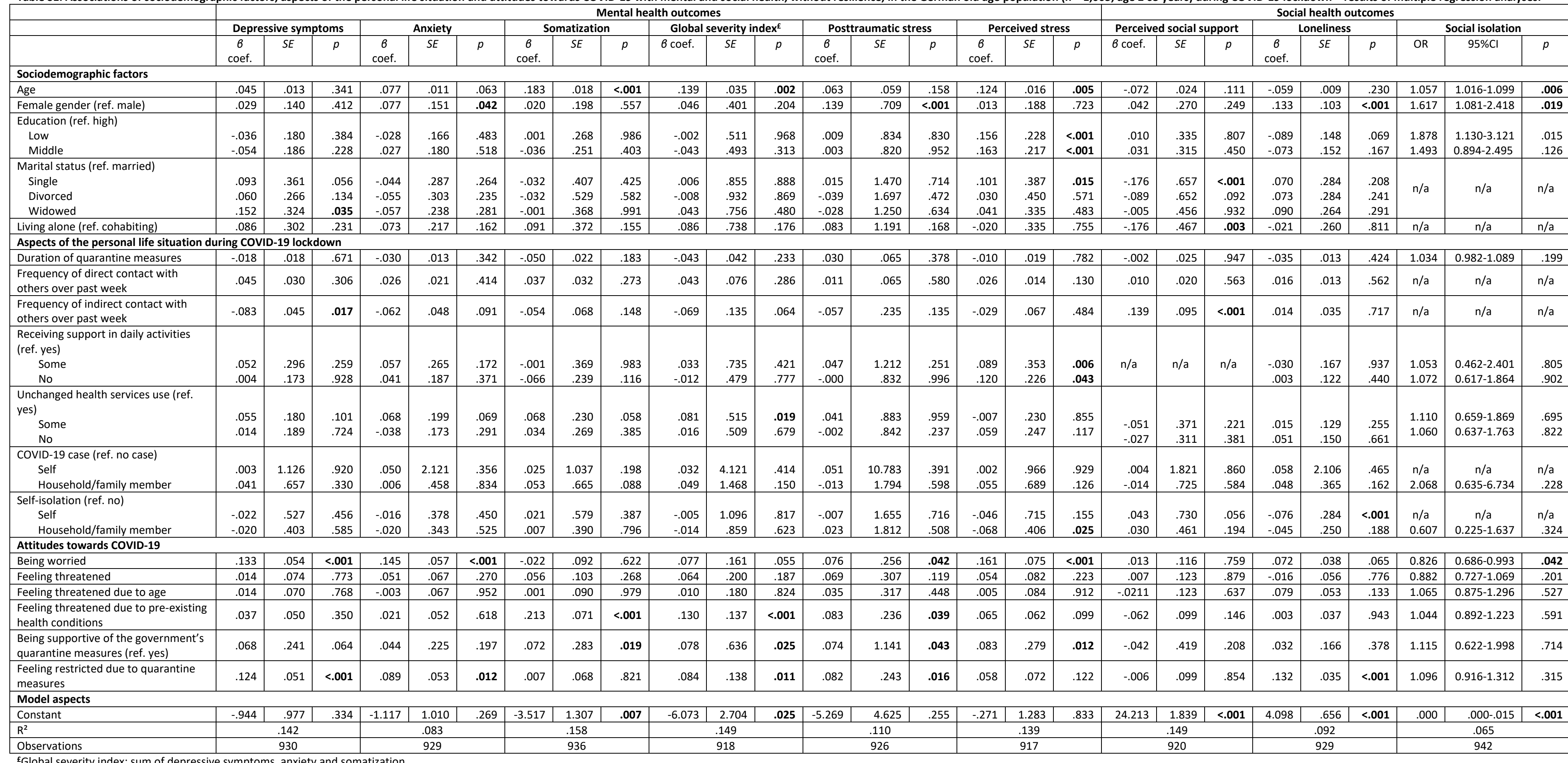

作

\begin{tabular}{ccccc}
929 & 936 & 918 & 926 & 917 \\
\hline
\end{tabular} 